\title{
A Study on the Application Mode of Foreign Media News Cases in Translation Teaching
}

\author{
Xihong Min ${ }^{1, *}$ \\ ${ }^{1}$ Foreign Languages School, Zhaotong University, Zhaotong, Yunnan, China \\ *Corresponding author. Email:583430200@qq.com
}

\begin{abstract}
The main purpose of this study is to explore the application mode of case-based teaching of foreign media news in translation teaching of undergraduates in application-oriented universities. By carrying out empirical research on case selection, case editing and the process and effect of case teaching of foreign media news, it is found that case-based teaching of foreign media news in translation can effectively improve students' cognition and understanding of translation.
\end{abstract}

Keywords: Case-based teaching, Foreign media news, Application mode, Translation teaching.

\section{INTRODUCTION}

With the globalization of information, the speed of news dissemination is getting faster and faster. News attracts a large number of readers with its timeliness and diversity of content. The application of foreign media news in translation teaching has similar attraction effect on students. Domestic news translation has developed since 2000, and its research frontiers mainly focus on six major topics, namely, text research, translation theory, translation strategies, methods and skills, influencing factors, social functions and translator studies, covering a relatively comprehensive range. Although the research topic of news translation also covers translation teaching, the results are very few. It is found that only 22 articles are actually related to translation teaching. These 22 articles mainly study the teaching of news translation from the aspects of corpus, the theory of "easy to read and write", the function of discourse, stylistic style, the reform of teaching mode and so on, which focus mostly on the teaching of "news translation" as a course. And there are few studies on translation teaching for English majors in applied universities. In the process of translation teaching, the author applies foreign media news cases to the process of translation teaching, in order to explore the role of

*Fund: Research Project (2019YN0014B): “Application of Foreign Media News to Translation Teaching of English Majors in Application-oriented Universities" of National Foreign Language Teaching Research Project of Higher Education. foreign media news case-based teaching mode in effectively mastering translation skills and improving translation ability, so that students can understand the true meaning of translation in the practice of translation.

\section{CHARACTERISTICS OF CASE- BASED TEACHING}

John Boether, former president of Harvard University's case-based teaching Association, argues that case-based teaching is a studentcentered approach and a process of interactive exploration of real problems and specific facts, the purpose of which is to cultivate students' ability to use their EQ and IQ to make decisions on complex problems under a certain amount of time, information and uncertainty. [1]

C. R. Christensen described case-based teaching as "the art of managing uncertainty", or a way to solve problems and cope with challenges. casebased teaching has the following four main features: (1) taking cases as teaching materials, encouraging students to think and cultivating the ability to solve problems in practice. (2) requiring positive interaction between teachers and students and between students through student-centered discussion. (3) The existence of questions is the key to case-based teaching, and the questions are often complex, and the answers are open and uncertain. (4) emphasizing practice and real cases to prepare 
students for their career. case-based teaching focuses on creating an innovative situational teaching mode with practicality, inspiration and flexibility. It improves students' comprehensive ability to find, analyze and solve problems by introducing, analyzing and discussing cases, and evaluating and summarizing them together. [2]

In the process of case-based teaching of translation, teachers should be creative and flexible, and attach great importance to the students' comprehension and creativity, achieve the combination of knowledge, ability, help students to lay a solid language foundation, improve the cultural quality, enhance the practical translation ability, and information communication skills.

\section{CASE TRANSLATION OF FOREIGN MEDIA NEWS AS A SUPPLEMENT TO TRADITIONAL TEACHING MODE OF TRANSLATION}

Traditional translation teaching focuses on the teaching of basic translation knowledge and skills, presenting the application of language translation skills from the aspects of word, sentence pattern to discourse translation. Although the given translation examples or materials also involve various fields such as economy, politics, culture, etc., most of them are outdated and are usually intercepted fragments, which lack complete context and cannot bring a complete experience of the translation process.

Using Foreign media news as the translation material can effectively make up for these defects. News is fresh, timely and interesting to read, which can effectively avoid students' lack of interest due to outdated translation materials. [3] The language of news is native, precise, popular and idiomatic, which meets the characteristics of translation materials. The length of news is moderate, and students can experience the complete translation process in a short time. Therefore, as a translation corpus, foreign media news can directly present the ultimate goal of learning translation theories and skills, stimulate students' independent thinking, and improve their translation ability.

\section{THE APPLICATION OF CASE TEACHING OF FOREIGN MEDIA NEWS TRANSLATION}

\subsection{Case Selection and Compilation}

The selection of cases is the first and foremost step in applying case-based teaching effectively to translation teaching. The selected news cases should be problematic, typical, targeted and timely, and should be in line with students' cognitive ability and translation level. As a local applicationoriented undergraduate university, the translation ability of English majors in Zhaotong University is generally not high. The selected news should be the subjects familiar to students in terms of content, and most of the vocabulary should belong to the common core vocabulary. Teachers should choose the latest news as the news case in order to arouse students' interest in translation. The case design should be open. In other words, there should be no standardized translation, which should be enlightening and provide students with multiple ways to think and translate. Typical cases can not only let students understand the typical translation situation and the way to solve the problem, but also achieve the effect of drawing inferences from other cases. Foreign media news is expected to be chosen from influential popular newspapers and magazines in English-speaking countries such as Newsweek, The New York Times, The Washington Post, Reader's Digest, Times, News Week, The News of the World, Nature and so on. It is worth mentioning that in the practice of the author's translation teaching, it is found that the news about China in native English newspapers and magazines can be good cases, as they are more familiar and more understandable to students, which can help students to analyze and translate with the theoretical knowledge of translation, and can effectively improve students' understanding of translation.

Case selection and compilation are often integrated. Ready-made news from foreign media is not necessarily an appropriate case for translation. It needs to be edited and processed to be suitable for the target students. When selecting and editing translation cases, the teacher should pay attention to two things: first, do not analyze the case, as analysis is the students' task; second, make the case fun to avoid students' aversion to the boring theory.[4] 


\subsection{Organization and Implementation of Case-based Teaching}

The case should be given to students in advance so that students can be fully prepared, including understanding the background and problems of the case and relevant translation theories. Before class, students can have group discussion, discuss the crux of the problem together, and integrate the views of group members, so that group representatives can present the result of group discussion in class. In class, first of all, the representatives of small groups present their translated text and give reasons when necessary. Second, the teacher helps students find out the difference between the translations of different groups and figure out the reasons of the difference on the basis of translation skills and techniques. Students can clarify their views, exchange ideas and jointly explore the best solution to translation problems. In the process of analyzing and solving practical translation problems, teachers should give necessary guidance to make the discussion closely related to the theme, thus to cultivate students' ability in critical thinking, creative thinking and solving problems.

Successful case translation teaching should be student-centered. The evaluation of students' study should be diversified, integrating self-evaluation, mutual evaluation among students and teacher's evaluation. Teachers should actively guide students to conduct serious self-evaluation and other evaluation and fully empower students with evaluation rights. [5] Effective evaluation can consolidate students' knowledge of translation, help them reflect on translation rules, and improve their translation competence.

The core of case-based teaching is discussion, the focus of which is the way to solve the problem in the case. In the teaching of translation course for English majors, an applied case of foreign media news is entitled "FERTILITY RATE RISING IN CHINA UNDER TWO-CHILD POLICY". In the translation of the phrase "TWO-CHILD", students present two different versions: “二胎” and “二孩”. The students are asked to discuss and understand the difference between the two versions. First, the discussion is carried out within the group. After the consensus is reached within the group, the discussion and analysis are carried out between the groups. Students figure out that “二胎” means two pregnancies while “二孩” means two children, and two pregnancies could mean more than two children as there are twins or triplets. In the end, it is agreed that “二孩” is the appropriate translation. This one small case has made a big difference in students' attitude towards translation. They understand that when translating, they need to check the official names of relevant policies, pay attention to current affairs, and treat translation with a rigorous attitude and a spirit of "seeking the truth".

\subsection{Possible Problems and Solutions in Case-based Teaching}

First, the relationship between case-based teaching and other teaching methods needs to be balanced. The limitation of case-based teaching is that it is not conducive to the acquisition of systematic knowledge. Therefore, the teaching of foreign media news cases can only be carried out after students have acquired some theoretical knowledge and practical experience, which should be arranged after the systematic study of translation theories and translation skills. Teachers should adopt different teaching methods flexibly according to teaching contents and teaching objectives, integrating the advantages of different teaching methods. [6]

Second, teachers should make full use of the means of network education and modern technology. For example, the selection of cases can be done via the internet by both the teacher and the students. The teacher gives some media links to students and students choose cases that are attractive to them from the given media links. Then the teacher decides and edits the case to be translated. Group discussion can be carried out through WeChat groups, QQ groups, Rain Classroom app, etc. This can save time, facilitate discussion, and improve the effect and quality of case-based teaching. The application of modern technology in students' translation practice is also essential. Students would be allowed to use machine translation, corpus, online information search and so on to explore the advantages and disadvantages and the application methods of these translation techniques and tools.

\section{CONCLUSION}

The case-based teaching of foreign media news as translation material is a new subject of innovative translation teaching, which has distinct practicality, interaction, openness and autonomy. Through the case-based teaching of foreign media 
news, "teacher-centered" teaching mode is changed to "student-centered", so as to improve the students' ability to apply translation skills in the practice of translation. In translation teaching, teachers should consciously ask students to read various types of English news materials, so that they can understand the linguistic features of news English and the writing norms of English news, which will help students to achieve appropriate translation which conforms to the stylistic characteristics of English news in terms of vocabulary, sentence pattern, discourse and writing style. Through the translation practice and the teacher's comments on foreign media news case, students are able to have a deeper understanding of the translation process - to be a qualified translator, the translator is required to be rigorous in his attitude towards translation, rich and comprehensive in his bilingual knowledge and skills, flexible in the use of translation skills, which is fundamental to make the translation more fluent, authentic and native to achieve equivalence of the translation to the original. In applying case-based teaching in translation teaching, teachers should pay attention to the complementarity of case-based teaching and other teaching methods, and focus on translation case development, case assessment and construction of case corpus.

\section{AUTHORS' CONTRIBUTIONS}

This paper is independently completed by Xihong Min.

\section{REFERENCES}

[1] Shi Rui. A Study on Innovative Translation Teaching Models: The Application of Casebased Teaching in Applied Translation Teaching $[\mathrm{J}]$. Journal of Mudanjiang University, 2012, 21(12):174-176.

[2] Christensen, C.R. Teaching and the Case Method [M]. Boston: Harvard Business School Press, 1987.

[3] Feng Quangong, Miao Ju. Practice of Casebased Teaching to Train Professional Translators: An Exploration of Translation Teaching Model of MTI [J]. Shandong Foreign Language Teaching, 2009, 30(06): 28-32.

[4] Tan Yesheng. Domain Dependent Cognitive Translation Teaching Model: A Case Study of Experimental Teaching Design for
Application-oriented Undergraduate Translation Majors [J]. Electronic Teaching of Foreign Languages, 2019 (05):62-68.

[5] Liu Heping. Translation Teaching Models: Theory and Application [J]. Chinese Translators Journal, 2013, 34(02):50-55.

[6] Wang Li, Dai Jianchun. Construction and Application of Interactive Translation Mobile Teaching Model Based on WeChat [J]. Foreign Language Teaching and Learning, 2015(02):35-41. 